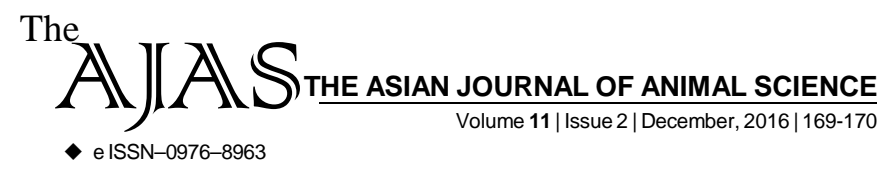

DOI : 10.15740/HAS/TAJAS/11.2/169-170
Visit us | www.researchjournal.co.in

RESEARCH NOTE

\title{
Leucas aspera treatment for ecto-parasitism in resistant cattle - Trial report
}

U. UMADEVI AND T. UMAKANTHAN

Author for Corresponding -

\section{T. UMAKANTHAN}

Veterinary Hospital, Sattur, VIRUDHUNAGAR (T.N.) INDIA

Email: sciencepot 1614

@ gmail.com

See end of the article for

Coopted authors'
ABSTRACT...... In a span of 1 year, in various veterinary institutions, 42 cattle were presented for external parasitic infestation with wide range of symptoms from discomfort to diseases transmitted by the parasites. On clinical and laboratory examination, various types of fleas and ticks identified in common. Control group, trail group A and B were formed with 2, 10 and 30 animals, respectively. Group A given regular allopathic treatment with Ivermectin or Flumethrin. Group B treated externally using the leaves of Leucas aspera at once. In the next 48 hours, recovery rate recorded was negligible in control group, 80 per cent and 93 per cent in group A and B, respectively. After a month clinical reinfestation noticed in group A animals, but not in group B.

KEY WORDS...... Cattle, External parasites, L.aspera

HOW TO CITE THIS ARTICLE - Umadevi, U. and Umakanthan, T. (2016). Leucas aspera treatment for ecto-parasitism in resistant cattle - Trial report. Asian J. Animal Sci., 11(2): 169-170. DOI : 10.15740/HAS/TAJAS/11.2/169-170.

ARTICLE CHRONICLE - Received : 13.09.2016; Accepted : 28.11.2016 